\title{
Altivitas Antioksidan dari Akar Bawang Daun (Allium fistulosum L.)
}

Sulistiawaty Udjailia*, Jemmy Abidjulua, Edi Suryantoa

aJurusan Kimia, FMIPA, Unsrat, Manado

\section{K A T A K U N C I}

Antioksidan

Radikal bebas

Allium fistulosum L.

\section{K E Y W O R D S}

Antioxidant

Free radical

Allium fistulosum L.

AVAILABLE ONLINE

10 Februari 2015

\begin{abstract}
A B S TR A K
Tujuan dari penelitian ini untuk menentukan aktivitas antioksidan yang terdapat dalam akar bawang daun. Penelitian dimulai dengan mendestilasi sampel akar bawang daun yang sudah dikering anginkan menggunakan cara destilasi uap dengan pelarut akuades, selanjutnya ditentukan kandungan total fenolik, flavonoid, tanin serta aktivitas penangkal radikal bebas DPPH. Hasilnya menunjukkan ekstrak fenolik dari akar bawang daun kering memiliki kandungan total fenolik, flavonoid dan tanin serta aktivitas penangkal radikal bebas yang paling baik untuk menangkal radikal bebas DPPH diikuti dengan ekstrak fenolik dari akar bawang daun segar.

A B S T R A C T

Objective of this research were to determine the antioxidant inside the onion root. The study was start with distilling the leek roots sample that have wind-dried using steam distillation with the solvent distilled water, and then determined the content of total phenolics, flavonoids, tannins and free radical prophylactic activity of DPPH. The results showed that the phenolic extract of the dried leaves of onion roots have total content of phenolic, flavonoid and tannin as well as the activity of free radical scavengers that are best to counteract free radical DPPH, this can be seen in free-radical scavengers activity test using DPPH test that phenolic extracts of onion root dry leaves is higher than the value percentage of phenolic extracts from fresh leaves of onion root.
\end{abstract}

\section{Pendahuluan}

Bawang daun (Allium fistulosum L.) merupakan salah satu jenis tanaman pangan yang sudah lama dikenal dan dibudidayakan di negara-negara berkembang. Pemanfaatan bawang daun sebagai sumber pangan menghasilkan limbah pada akar bawang daun yang pada umumnya dibuang. Bawang daun merupakan salah satu jenis sayuran daun yang dibudidayakan sebagai bahan sayuran (daun dan batang) dan bahan obat (akar, batang dan daun) (Cahyono, 2005). Dalam pengobatan tradisional tanaman bawang daun digunakan untuk mengobati masuk angin atau pilek, yang dikombinasikan dengan tumbuhan lain, selain itu digunakan juga untuk mengurangi gejala hidung berlendir, demam, rasa dingin, serak, dan sakit kepala. Pada bagian akar direkomendasikan untuk mengobati pilek, sakit kepala, sakit tenggorokan dan luka-luka. Biji bawang daun juga dianggap dapat meningkatkan fungsi ginjal (Sujitno et al, 2003). Pemanfaatan akar bawang daun tersebut masih berkurang dan diduga limbah akar bawang daun tersebut mengandung senyawasenyawa kimia yang mempunyai aktivitas sebagai penangkal radikal bebas atau antioksidan. Oleh karena itu, perlu dilakukan uji aktivitas antioksidan, sehingga hasil penelitian ini diharapkan dapat memberikan informasi tentang aktivitas antioksidan yang terdapat pada akar bawang daun.

\section{Metode}

Sampel yang akan digunakan pada penelitian ini adalah akar bawang daun diperoleh dari pasar tradisional di kota Manado. Bahan kimia yang digunakan yaitu etanol, reagen Folin Ciocalteu, natrium karbonat, alumunium klorida, vanilin, asam

*Corresponding author: Jurusan Kimia FMIPA UNSRAT, Jl. Kampus Unsrat, Manado, Indonesia 95115; Email address: sulisudjaili@ymail.com 
klorida, asam tiobarbiturat (TBA), asam trikloroasetat (TCA), 1,1-difenil-2-pikrilhidrazil (DPPH) diperoleh dari Sigma (St. Louis, USA) serta akuades. Peralatan yang digunakan dalam penelitian ini adalah mikropipet, seperangkat alat destilasi, alat evaporator, dan centrifuge Eba Hettich.

\subsection{Preparasi Sampel}

Sampel akar bawang daun dicuci terlebih dahulu sampai bersih kemudian sampel dipisahkan menjadi dua yaitu sampel segar dan sampel kering, untuk sampel kering dikering anginkan selama kurang lebih satu minggu.

\subsection{Destilasi}

Sampel segar sebanyak $1000 \mathrm{~g}$ dan sampel kering $80 \mathrm{~g}$, dimasukkan ke dalam labu yang telah berisi aquades. Air dialirkan ke kondensor dan dijaga agar air terus mengalir. Destilat yang diperoleh merupakan campuran minyak dengan air yang selanjutnya dipisahkan dan dipekatkan dengan menggunakan rotary vacuum evaporator sehingga menjadi ekstrak.

\subsection{Penentuan Kandungan Total Fenolik, Flavonoid, dan Tanin Terkondensasi}

Kandungan total fenolik ekstrak akar bawang daun ditentukan dengan menggunakan metode FolinCiocalteau (Conde et al, 1997). Absorbansinya dibaca pada $\lambda 750 \mathrm{~nm}$ dengan spektrofotometer. Kandungan total fenolik dinyatakan sebagai mg ekivalen asam galat/L. sampel. Penentuan kandungan total flavonoid menggunakan metode Meda et al. (2005). Absorbansinya dibaca pada $\lambda 415$ $\mathrm{nm}$. Kandungan total flavonoid dinyatakan sebagai $\mathrm{mg}$ ekivalen asam galat/L. sampel. Penentuan kandungan total tanin ditentukan menurut metode Julkenen-Tito (1985). Absorbansi sampel dibaca pada $\lambda 500 \mathrm{~nm}$. Kandungan total tanin dinyatakan sebagai mg ekivalen katekin/L sampel.

\subsection{Penentuan Aktivitas Penangkal Radikal Bebas DPPH}

Penentuan aktivitas penangkal radikal bebas DPPH ditentukan dengan menggunakan metode (Burda et al., 2001). Sebanyak 0,5 mL ekstrak 1 $\mathrm{mg} / \mathrm{mL}$ ditambahkan dengan $2 \mathrm{~mL}$ larutan 1,1-difenil2-pikrilhidrazil (DPPH) $93 \mu \mathrm{M}$ dalam etanol dan divorteks selama 2 menit. Tingkat memudarnya warna pada larutan dari warna ungu menjadi warna kuning menunjukan efisiensi penangkal radikal bebas. Selanjutnya diinkubasi selama 30 menit pada suhu ruang. Absorbansinya diukur pada $\lambda 517 \mathrm{~nm}$ dengan menggunakan spektrofotometer UV-Vis . Aktivitas penangkal radikal bebas dihitung sebagai persentase berkurangnya warna DPPH dengan menggunakan persamaan: (1- absorbansi sampel/ absorbansi kontrol) x 100\%.

\section{Hasil dan Pembahasan}

\subsection{Destilasi Sampel}

Proses destilasi ini menggunakan sampel akar bawang daun yang dibagi menjadi dua sampel yaitu sampel segar dan kering. Untuk sampel segar telah diuji kadar air terlebih dahulu yaitu sebesar $88,79 \%$ dan sampel kering sebesar 15,49\%. Selanjutnya proses destilasi $1000 \mathrm{~g}$ akar bawang daun segar dengan menggunakan pelarut aquades $2.400 \mathrm{~mL}$ menghasilkan ekstrak sebanyak 2,04 g dengan warna coklat tua, sehingga menghasilkan rendemen sebesar $0,20 \%$. Kemudian proses destilasi 80 g akar bawang daun kering dengan menggunakan pelarut aquades $1.600 \mathrm{~mL}$ menghasilkan ekstrak sebanyak 5,83 g dengan warna coklat tua, sehingga menghasilkan rendemen sebesar 7,29\%.

\subsection{Penentuan Kandungan Total Fenolik, Flavonoid dan Tanin}

Hasil Ekstrak dari akar bawang daun segar dan kering dibuat dengan konsentrasi 20.000 ppm kemudian diuji kandungan total fenolik, flavonoid, dan tanin. Hasil analisis kandungan total fenolik, flavonoid, dan tanin yang diperoleh di sajikan pada Tabel 1.

Tabel 1 - Kandungan Total Fenolik, Flavonoid, dan Tanin dari Ekstrak Akar Bawang Daun

\begin{tabular}{|l|c|c|c|}
\hline Ekstrak & $\begin{array}{c}\text { Total } \\
\text { Fenolik } \\
(\mathrm{mg} / \mathrm{L})\end{array}$ & $\begin{array}{c}\text { Total } \\
\text { Flavonoid } \\
(\mathrm{mg} / \mathrm{L})\end{array}$ & $\begin{array}{c}\text { Total } \\
\text { Tanin } \\
(\mathrm{mg} / \mathrm{L})\end{array}$ \\
\hline $\begin{array}{l}\text { Sampel } \\
\text { Segar }\end{array}$ & 132,04 & 9,72 & 14,08 \\
\hline $\begin{array}{l}\text { Sampel } \\
\text { Kering }\end{array}$ & 152,14 & 10,71 & 14,69 \\
\hline
\end{tabular}

Berdasarkan Tabel 1 diketahui bahwa ekstrak akar bawang daun memiliki kandungan total fenolik lebih tinggi pada sampel kering diikuti dengan ekstrak akar bawang daun segar yaitu 152,14 mg/L, ini disebabkan senyawa fenol mencakup sejumlah senyawa-senyawa yang umumnya mempunyai sebuah cincin aromatik dengan satu atau lebih gugus hidroksil (Geisman \& Crout, 1969). Pengujian kandungan total fenolik bertujuan untuk menentukan total senyawa fenolik yang terkandung di dalam sampel, sehingga diduga bila kandungan senyawa fenolik di dalam sampel tinggi maka aktivitas antioksidannya akan tinggi. Kandungan dengan metode Folin-Ciocalteau ditunjukkan dengan adanya perubahan warna larutan dari kuning menjadi biru yang di karenakan reagen Folin-Ciocalteau mengandung senyawa asam fosfomolibdatfosfotungstat yang kemudian membentuk senyawa kompleks molibdenum tungstant berwarna biru, semakin pekat intensitas warnanya menandakan semakin tinggi kandungan total fenol didalam ekstrak (Julkunen-Tiito, 1985).

Kandungan total flavonoid untuk ekstrak akar bawang daun memiliki nilai flavonoid lebih tinggi pada sampel kering diikuti dengan ekstrak akar bawang daun segar yaitu 10,71 mg/L. Tingginya kandungan total flavonoid pada ekstrak menunjukkan bahwa flavonoid merupakan senyawa yang memiliki sifat 
kepolaran yang lebih tinggi dibandingkan dengan senyawa-senyawa fenolik yang lain, itulah sebabnya flavanoid lebih suka larut pada ekstrak dengan pelarut yang memiliki kandungan air yang banyak. Flavonoid dapat membentuk kompleks dengan logam $\mathrm{Al}^{3+}$ pada gugus hidroksi dan keton yang dapat menghasilkan warna kuning, sehingga dapat disimpulkan bahwa semakin kuat intensitas warna kuning maka kandungan flavonoid yang terkandung dalam ekstrak akan semakin tinggi (Meda et al, 2005).

Kandungan total tanin untuk ekstrak akar bawang daun memiliki nilai tanin lebih tinggi pada sampel kering diikuti dengan ekstrak akar bawang daun segar yaitu yaitu sebesar $14.69 \mathrm{mg} / \mathrm{L}$. Kandungan tanin tersebut berpengaruh terhadap aktivitas antioksidan karena tanin merupakan salah satu antioksidan alami dalam tumbuhan. Prinsip uji vanilin- $\mathrm{HCl}$ dalam penentuan kandungan tanin terkondensasi yaitu vanilin terprotonasi dalam asam membentuk karbokation dan bereaksi dengan flavonoid. Senyawa antara yang dihasilkan mengalami reaksi dehidrasi senyawa berwarna ungu atau merah.

\subsection{Aktivitas Penangkal Radikal Bebas DPPH}

Aktivitas penangkal radikal bebas menggunakan uji DPPH dari ekstrak akar bawang daun dalam keadaan segar dan kering dapat dilihat pada Gambar 1.

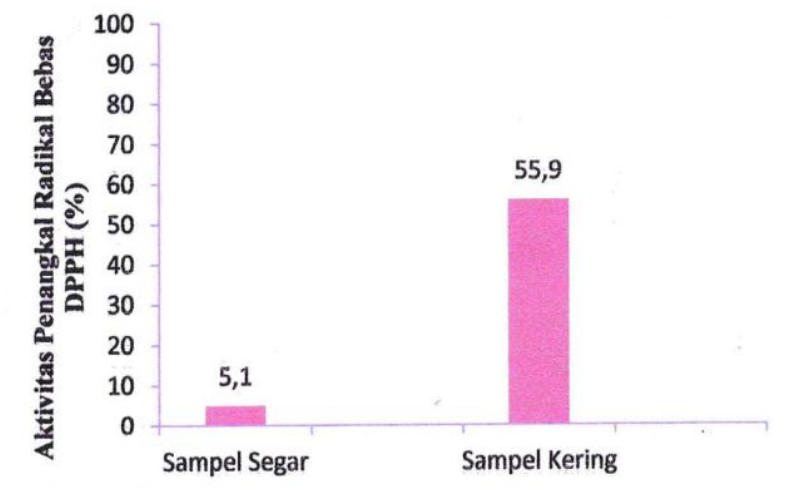

Gambar 1 - Aktivitas Penangkal Radikal Bebas dari Akar Bawang Daun Segar dan Kering.

Senyawa radikal bebas digunakan untuk mengetahui aktivitas penangkapan radikal bebas. Dalam penelitian ini menggunakan radikal bebas DPPH. Aktivitas penangkal radikal bebas menggunakan uji DPPH dari ekstrak akar bawang daun dalam keadaan segar dan kering dapat dilihat pada Gambar 1 yang menunjukkan bahwa ekstrak akar bawang daun kering memiliki nilai persentase DPPH lebih tinggi diikuti dengan ekstrak akar bawang daun segar yaitu dengan nilai 55.9\%. Hal ini menunjukan kemampuan senyawa antioksidan yang terdapat dalam ekstrak untuk mendonorkan atom hidrogennya yang akan bereaksi dengan radikan bebas DPPH sehingga terbentuk senyawa non radikal DPPH (DPPH-H stabil). Metode DPPH didasarkan pada penurunan nilai absorbansi akibat perubahan warna larutan yang mula-mula ungu berubah menjadi kuning. Perubahan ini terjadi saat radikal DPPH ditangkap oleh antioksidan yang melepaskan hidrogen dalam bentuk DPPH-H stabil (Molyneux, 2004).

\section{Kesimpulan}

Ekstrak akar bawang daun memiliki kandungan total fenolik, flavonoid, dan tanin lebih tinggi pada akar bawang daun sampel kering diikuti ekstrak fenolik dari akar bawang daun sampel segar. Dari data aktivitas penangkal radikal bebas menunjukkan bahwa semakin besar konsentrasi ekstrak akar bawang daun, maka semakin meningkat juga aktivitas antioksidan, ekstrak akar bawang daun sampel kering mempunyai aktivitas yang baik untuk menangkal radikal bebas DPPH.

\section{Daftar Pustaka}

Burda, S., dan W. Oleszek. 2001. Antioxidant and Antiradical Activities of Flavonoids. Journal Agricultural Food Chemistry. 49: 2774-2779.

Cahyono, B. 2005. Bawang Daun: Teknik Budi Daya dan Analisis Usaha Tani. Kanisius, Yogyakarta.

Cai, Y., Luo, Q., Sun, M, dan H. Corke. 2003. Antioxidant Activity and Phenolic Compounds of 112 Tradisional Chinese Medicinal Plants Associated with Anticancer. Life Science. 74: 2157-2184.

Conde, E., Cadahia, E., Gracia, M.C., Vallejo, B.F.D., Simion, dan J.R.G. Adrados. 1997. Low molecular weight polyphenol in cork of quercus suber. Journal Agriulturalc Food Chemistry. 45: 26952700.

Geisman T. A., dan D.H.G. Crout. 1969. Organic Chemistry of Secondary Plant. Metabolisme. Freeman Cooper and Co, Caifornia.

Halliwel, B., dan J.M.C. Gutteridge. 2001. Free Radicals in Biology and Medicine. Oxford University Press, New York.

Harbone, J. B. 1987. Metode Fitokimia Penuntun Cara Modern Menganalisis Tumbuhan. Terjemahan Padmadinata, K., dan I. Soediro. ITB, Bandung.

Julkenen-Titto, R. 1985. Phenolic Constituents in the Leaves of Northern Willows: Methods for the Analysis of Certain Phenolic. Journal Agricultural Food Chemistry. 33: 213-217.

Meda, A., C.E. Lamien, M. Romito, J. Milliogo, dan O.G. Nacoulina. 2005. Determination of the Total Phenolic, Flavonoid and Proline Content in Burkina Fasan Honey, as well as Their Radical Scavenging Activity. Journal of Food Chemistry. 91: 571-577.

Miller, M.J., Sadowska-Krowicka, H., Chotinaruemol, S., Kakkis, J.L, dan D.A. Clark. 1993. Amelioration of chronic ileitis by nitric oxide synthase inhibition. Journal of Pharmacology and Experimental Therapeutics. 264: 11-16 
Molyneux, P. 2004. The Use of the Stable Free Radical Diphenylpicrylhidrazyl (DPPH) for Estimating Antioxidant Activity. Songklanakarin Journal of Science and Technology. 26: 211-219..
Sujitno, E., dan T. Fahmi. 2003. Aplikasi Pestisida Nabati Mendukung Potensi Bawang Daun Sebagai Pangan Fungsional. Seminar Nasional Pangan Fungsional. 71-77. 